DOI: $10.5216 /$ racs.v6.67758

\title{
Diálogo intercultural no agreste e sertão pernambucanos: o Povo Pankará e os/ãs Artesãos/ãs do Alto do Moura
}

\author{
Jaqueline Barbosa da Silva ${ }^{1}$ \\ Everaldo Fernandes da Silva ${ }^{2}$ \\ Maria Luciete Lopes ${ }^{3}$ \\ William Francisco da Silva ${ }^{4}$
}

\section{RESUMO}

O presente trabalho enseja evidenciar um diálogo intercultural entre as cosmovisões dos/as artesãos/ãs do Alto do Moura - Caruaru/PE e do Povo Pankará, cuja percepção é resultado dos desdobramentos do Programa Institucional de Bolsas de Iniciação à Docência para a Diversidade (PIBID Diversidade), do projeto de pesquisa Professores Indígenas de Pernambuco: formação, pesquisa e prática pedagógica, das rodas de diálogo com os referidos ceramistas e, teoricamente, das lentes dos estudos pós-coloniais (ESCOBAR, 2003; MIGNOLO, 2007; MALDONADO-TORRES, 2007). A dinâmica do PIBID Diversidade, do Campus Agreste da Universidade Federal de Pernambuco (UFPE), tem assento, neste trabalho, nas práticas formativa e educativa do Povo Pankará e dos/as artesãos/ãs do Alto do Moura. Este caminho foi, paritariamente, construído em articulação com a Comissão dos Professores Indígenas de Pernambuco (COPIPE), os/as artesãos/ãs do Alto do Moura, os/as participantes indígenas do PIBID Diversidade e colaboradores/as vinculados à universidade. As estratégias metodológicas utilizadas filiam-se às perspectivas do movimento recursivo, rompendo com a linearidade colonialista das ações societárias que privilegiam os saberes escolares urbanocêntricos e governamentais. $\mathrm{O}$ acesso às cosmovisões do Povo Pankará e os contatos intersubjetivos dos/as artesãos/ãs do Alto do Moura revelaram as práticas educativas e a produção do conhecimento popular promovendo um olhar críticopropositivo no e do grupo dos/as participantes indígenas e artesãos/ãs. Em ambos contextos, dos saberes indígenas e artesãos/ãs, as cosmovisões e formações distintas complementam-se, com assento, seja na valorização e respeito aos saberes tradicionais, seja, na oralidade e no cotidiano, cujas percepções e juízos de valor são herdados e transmitidos individual e coletivamente.

PALAVRAS-CHAVE: PIBID Diversidade. Povo Pankará. Artesãos/ãs do Alto do Moura. Interculturalidade. Narrativas Autobiográficas.

\footnotetext{
${ }^{1}$ Universidade Federal de Pernambuco (UFPE), Recife, Pernambuco, Brasil. E-mail: jaqueline.barbosa@ufpe.br. 2 Universidade Federal de Pernambuco (UFPE), Recife, Pernambuco, Brasil. E-mail: everaldofernandes.silva@gmail.com.

${ }^{3}$ Coordenadora da Gestão da Educação Escolar Indígena- Povo Pankará. E-mail: lucietepankara@hotmail.com. 4 Secretaria Municipal de Educação de Arcoverde, Arcoverde, Pernambuco, Brasil. E-mail: william2007silva@hotmail.com.
} 


\title{
Intercultural dialogue in the Agreste e Sertão of Pernambuco: the Pankará people and the craftspeople from Alto do Moura
}

\begin{abstract}
This work gives rise to highlighting an intercultural dialogue between the cosmovisions of the craftspeople from Alto do Moura - Caruaru/PE and the Pankará people, whose perception is the outcome of the deployment strategies of the Institutional Program of Scholarships as an introduction to Teaching for Diversity (PIBID Diversity), from the research project Professores Indígenas de Pernambuco (Indigenous Teachers of Pernambuco): professional training, research and pedagogical practice, from dialogue circles with the aforementioned potters and, theoretically, from the lenses of postcolonial studies (ESCOBAR, 2003; MIGNOLO, 2007; MALDONADO-TORRES, 2007). The dynamics of PIBID Diversidade, from the Agreste Campus of the Federal University of Pernambuco (UFPE), has a place of prominence, in this work, on the formational and educational practices of the Pankará people and of the craftspeople from Alto do Moura. This path was, jointly, built in a close liaison with the Indigenous Teachers Commission of Pernambuco (COPIPE), the craftspeople from Alto do Moura, the indigenous participants of PIBID Diversidade and associates bound to the university. The methodological strategies employed join the perspectives of the recursive movement, breaking with the colonialist linearity of societal actions which favor urban-centric and governmental school sets of learning knowledge. Access to the cosmovisions of the Pankará people and the intersubjective contacts of the craftspeople from Alto do Moura revealed the educational practices and the production of popular knowledge, fostering a critical proposition stance at and among the group of indigenous participants and craftspeople. In both contexts, from indigenous and craftspeople's sets of knowledge/wisdom, the cosmovisions and distinct life experiences complement each other, at least prominently, either in the appreciation and respect to traditional knowledge, or in orality and daily life, whose perceptions and value judgments are inherited and transmitted individually and collectively.
\end{abstract}

Keywords: PIBID Diversity. Pankará People. Craftspeople from Alto do Moura. Interculturality. Autobiographical Narratives.

\section{Introdução}

O PIBID Diversidade vem promovendo a produção de conhecimento, contribuindo com a qualificação do ensino e da aprendizagem na educação básica das escolas Pankará, a partir da articulação entre os conhecimentos adquiridos pelos/as Pankará na universidade com os saberes próprios do Povo. Essa troca de saberes estimula, ainda mais, os/as pibidianos/as para que se coloquem numa postura investigativa com práticas de pesquisa geradoras de conhecimentos significativos, levando em conta as questões históricas, socioculturais e ambientais como também as diversas experiências vividas no cotidiano das aldeias, dialogando com os conhecimentos das demais sociedades.

Assim, as aprendizagens vão se fortalecendo tanto para os/as universitários/as indígenas quanto para os/as estudantes das escolas do Povo. A interação das ações do PIBID com as ações da gestão escolar vai se constituindo através da prática coletiva na construção do saber, 
valorizando o processo de elaboração e execução das atividades do referido Programa. Nesta perspectiva, o PIBID Diversidade, através das ações desencadeadas por meio dos projetos desenvolvidos na segunda edição (2014-2018) $)^{5}$, possibilitaram ampliar as lentes de compreensão da dimensão do conhecimento na perspectiva de compreender a função social da educação escolar indígena e o projeto societário do Povo.

Doutra parte, os/as artesãos/ãs do Alto do Moura ${ }^{6}$, de Caruaru, Pernambuco, que há mais de um século, desenvolvem atividades com o barro, transitando dos utensílios domésticos aos bonecos representativos das lutas ininterruptas dos nordestinos pela sobrevivência, produzem seus saberes recontando suas histórias de vida, construindo seus conhecimentos em versos e prosas e tecendo visões de mundo associadas ao cotidiano, às heranças ancestrais e à imaginação humana.

O presente artigo tem como base teórico-epistemológica a perspectiva pós-colonial e a Educação Popular para compreender as dinâmicas de resistência e as estratégias de superação tanto do Povo Pankará, em seus modos ensinantes e aprendentes e das suas cosmovisões, bem como dos/as ceramistas no agreste pernambucano que produzem, além da arte em barro, novos sentidos, signos e ressignificações para sobreviver material e simbolicamente.

Neste artigo, refletimos não uma luta intercultural entrópica, mas um jeito aproximativo de produzir interculturalidade entre o sertão e o agreste pernambucanos, entre povos do campo e da cidade, bem como entre as cosmovisões que se aproximam pelo horizonte comum das resistências e das cosmovisões que reinventam sentidos novos e modos inteligentes de driblar os modelos imperialistas do neoliberalismo.

\section{A educação para além do processo de escolarização: os itinerários inventivos-formativos de sujeitos da educação popular}

\footnotetext{
${ }^{5}$ O programa contemplou os projetos Bem Viver e Tecnologias, Gestão da Educação Escolar Indígena, Educação Inclusiva, Língua, Leitura e Produção de Textos, Arte indígena, Saberes tradicionais e Processos Próprios de Ensino e Aprendizagem, para maiores detalhes, cf. Silva; Silva (2015).

${ }^{6}$ Bairro localizado a $7 \mathrm{~km}$ do centro de Caruaru. Neste território, um quantitativo significativo da população é constituída de ceramistas, que participam das várias fases da feitura das peças artísticas em barro: a coleta, o amaciamento, a modelagem criativa ou reprodutiva, o acabamento, a queima, a pintura, as embalagens e a entrega final dos produtos, cf. Silva (2011). Outrossim, neste chão começou a saga dos/as artesãos/ãs, que tem como principal personagem o Mestre Vitalino. Na atualidade, o local representa um dos mais significantes centros de artes figurativas das Américas. Lá, o visitante pode encontrar a Casa-Museu Mestre Vitalino, Memorial Mestre Galdino, ateliês, bares e restaurantes de culinária regional e, de acordo com o calendário de eventos da cidade, polos de atrações culturais. Disponível em: 〈https://www.mapacultural.pe.gov.br/espaco/267/〉. Acesso em dez./2020.
} 
A educação no ocidente, durante séculos, fora compreendida e atestada, por alguns pensadores, como um processo formativo gerenciado pela compreensão de ensino e aprendizagem, exclusivamente mediado e sistematizado pela instituição escolar, resguardando a incumbência do professor de transmitir os conteúdos aos seus alunos. Ao longo do desenvolvimento de práticas pedagógicas inovadoras e progressistas e a organização e a resistência de movimentos sociais e populares em torno das compreensões acerca da educação, o paradigma que partia da restrita tarefa do educador de transmitir saberes, limitado ao âmbito escolar, tornou-se insipiente para se alcançar a mudança social tão urgente e tão necessária para a sociedade hodierna.

Atualmente, passamos a entender da seguinte maneira: "o educador, o intelectual engajado, cimentado com o oprimido, não pode limitar-se a conscientizar dentro da sala de aula. Deverá aprender a se conscientizar com a massa" (FREIRE, 2008, p. 12). A pedagogia freireana endossa a fileira de tantos outros sujeitos que têm pensado numa educação para além dos muros escolares. A educação não-escolar, fomentada por mulheres e homens trabalhadoras/es, negras/os, indígenas, camponeses/as, populações $\mathrm{LGBT}^{7}$, ativistas de movimentos populares, associações, poetas/poetisas, cordelistas e artesãos/as, suplanta a compreensão dominante de conhecimento e assume o caráter de incompletude ${ }^{8}$ cimentado e validado pelo currículo escolar e inaugura um novo modo de se produzir e socializar conhecimentos. Para além, com os seus jeitos próprios de refletir e interpretar o mundo e as relações vitais, esses povos, historicamente excluídos pelo saber colonial, forjam uma filosofia popular, crítico-reflexiva, capaz de denunciar as injustiças e exclusões sociais e engendrar processos educativos conscientizadores e humanizantes.

Em meio a um contexto de educação enquanto construção cultural e humana, forjada pelos sujeitos em movimentos permanentes de interação, reflexão, ressignificação e ação, decidimos gestar uma investigação sobre as visões de mundo latentes nesses sujeitos artesãos do Alto do Moura e as suas formas de tradução, mediante a organização dos seus discursos, narrativas e representações da vida na poesia, nos encontros coloquiais ou nas obras de arte.

\footnotetext{
${ }^{7}$ Nesse artigo, optamos pelo uso da sigla LGBT e estamos cientes de que essas letras podem se tornar insuficientes diante da amplitude da população que contempla a diferença de sexualidade. Para os/as que desejarem aprofundar a discussão sobre as contribuições do currículo da formação de professores/as para a prática pedagógica com gênero e sexualidade na Educação Básica, cf. Santos (2016).

${ }^{8}$ Baseamo-nos na compreensão de conhecimento poderoso, cf. Young (2011), para evidenciar as diferentes histórias, tradições e modos de trabalhar, permitindo a distribuição mais justa e igualitária do mundo em que vivemos.
} 
O caminho hermenêutico que fizemos sugeriu-nos que os dados coletados não fossem tratados/compreendidos no jogo ou lógica interpretativos de forma pura, translúcida e autêntica das cosmovisões dos/as Povo Pankará e dos sujeitos artesãos do Alto do Moura, mas uma aproximação das suas possíveis leituras de mundo comportando contradições, espectros, buscas e mecanismos de superação das condições adversas que vivem.

Trata-se, evidentemente, de uma estrutura híbrida que muito caracteriza as expressões de um povo dominado e de cultura historicamente subalternizada, cujas feições de pensamento, de expressões e comunicações potencializam a amplificação das pesquisas tanto da Educação Popular, como da Educação do Campo e de Educação de Jovens e Adultos.

Na Educação Popular, é primordial o entendimento que concebe esse modelo como uma educação do povo, com o povo e para o povo, porque parte das vivências históricas e culturais das/os educandas/os, valorizando seus saberes apreendidos ainda no seio familiar ou na vida em comunidade, isto é,

[...] no interior de uma vida coletiva anterior à escola, mas plena de educação, os homens entre si se ensinam-e-aprendem. Ao mesmo tempo que socialmente a educação, um domínio da cultura entre outros, é condição da permanente recriação da própria cultura, individualmente a educação, uma relação de saber entre trocas de pessoas, é condição da criação da própria pessoa (BRANDÃO, 2012, p. 23).

Esse processo de recriação permanente da cultura estimula o protagonismo daqueles/as subalternizados/as pela cultura dominante. Isto é, a Educação Popular se torna um grande meio viabilizador de libertação dos oprimidos, consolidando-se como instrumento denunciador e repugnante ao epistemicídio e inspirador de pedagogias de libertação/emancipação, coordenadas por sujeitos-atores/atrizes inferiorizados/as ao longo da história oficial (ARROYO, 2014).

O desdobramento da Educação Popular nas classes menos favorecidas, de modo especial, nos movimentos populares sociais (campo, cidade, etnia, LGBT, etc), Organizações da Sociedade Civil (OSCs), associações de moradores de bairro, centros de cultura, entre outros, evidencia um processo de luta coletiva por democratização da política educacional e o reconhecimento das novas epistemologias produzidas a partir do cotidiano. Entendido até então como o não-lugar, o cotidiano passou a ser compreendido, sobretudo, a partir das contribuições das epistemologias do Sul (SANTOS; MENESES, 2010) e dos estudos pós-coloniais como o lugar da reinvenção e da produção de saberes outros. Assim, 
a educação popular constitui uma prática referida ao fazer e ao saber das organizações populares, que busca fortalecê-la enquanto sujeitos coletivos, e assim, contribuir através de sua ação-reflexão ao necessário fortalecimento da sociedade civil e das transformações requeridas, tanto para a construção democrática de nossos países, como para o desenvolvimento econômico com justiça social (WANDERLEY, 2010, p. 25).

Essa relação vida e conhecimento é fundante nos processos de construção dos novos saberes para a vida, despertando nos sujeitos aprendizes uma releitura de mundo, uma nova percepção crítica sobre a realidade que os circunda e que os integra. Em outras palavras, a abertura que a educação popular propõe ao levar em conta os saberes ancestrais, os mitos, a religiosidade popular, pode proporcionar uma reviravolta na concepção de educação e mais precisamente no modo como essas populações refletem e interpretam a vida e suas interrelações, consequentemente uma nova percepção de mundo e de gente, simbolicamente uma construção autêntica de uma filosofia popular.

Seguindo essa esteira compreensiva, situamos as condições possibilitadoras e limitativas que engendram tanto os contextos donde emergem as leituras de mundo que aproximam os sujeitos inventivos do Povo Pankará e do Alto do Moura, bem como os aspectos gerais das suas cosmovisões.

\section{Compreensão decolonial das práticas educativas Pankará}

O território sagrado do Povo Pankará é a Serra do Arapuá, local de habitação e sobrevivência e seu mais importante espaço de produção de sentido. É nele que as famílias indígenas mantêm-se economicamente e reafirmam os laços culturais e interculturais.

O Povo Pankará da Serra do Arapuá está localizado no sertão de Pernambuco, no município de Carnaubeira da Penha, há aproximadamente 500 quilômetros da capital pernambucana. Neste local de habitação e sobrevivência, as famílias indígenas mantêm-se economicamente e reafirmam os laços culturais e interculturais. A população, identificada pelo conselho de ancião, até 2018 é de aproximadamente 5.500 índios. A organização sócio-política do Povo é constituída a partir do sagrado, organizado através do Conselho de anciãos, composta por pajés, cacique e lideranças ${ }^{9}$ de aldeia e a organização interna de educação.

\footnotetext{
${ }^{9}$ São lideranças as pessoas indicadas pela natureza e pelos encantos de luz. Ou seja, quem detém o saber religioso e guarda a história do Povo.
} 
O Povo mantém a cultura com a dança do Toré ${ }^{10}$, o artesanato, a agricultura tradicional, as ervas medicinais, as histórias antigas e os rituais sagrados. O Toré e os anciãos são as forças maiores do Povo. A liderança religiosa é a base da identidade e da educação. A educação escolar indígena respeita a organização social, o espaço geográfico e as relações familiares, retratando a realidade sociocultural do Povo.

Assim, no território tradicional existem 29 (vinte e nove) aldeias, com unidades escolares. As escolas estão organizadas em seis núcleos, de acordo com a distribuição territorial Pankará, que delimitam o território a partir do sagrado e contribuem para o processo de demarcação da terra e a permanência do Pankará na terra sagrada. E, para um melhor acompanhamento pedagógico das ações, em termos da educação escolar, desde 1940, uma das frentes de luta do Povo voltava-se para o reconhecimento e a demarcação da terra, reconhecida oficialmente em 2003 e identificada nos seus limites em 2010.

A educação escolar indígena proporciona a compreensão das relações humanas estabelecidas no território, organizam as mobilizações e os movimentos no Povo, estrutura os saberes, possibilita o registro da memória e história, fortalece a identidade e a vivência do Povo repassando as tradições e valores para a melhoria da qualidade de vida e a garantia da aprendizagem. As aprendizagens nela construídas são formas de fortalecimento da cultura e articulação entre diferentes conhecimentos.

Nesse sentido, a escola objetiva formar guerreiros e guerreiras, lutadores pelo bem-estar do Povo Pankará, para que esse busque os seus direitos, direitos esses de lutar e manter a sua identidade, a valorização da sua cultura, que saiba defender suas tradições em qualquer lugar e circunstâncias. E mais, deve ser praticante dos costumes, crenças, saberes tradicionais, e que respeite o território sagrado como espaço de luta, conquista e de práticas do bem viver como a partilha, a superação das dificuldades, o cuidado e proteção aos bens naturais e históricos e o respeito à diferença, preparando-se para a convivência numa sociedade intercultural.

Os/as universitários/as-bolsistas Pankará são educadores/as no Povo e, também, lideranças no sentido que participam ativamente dos problemas nas aldeias e procuram refletir constantemente com os estudantes e responsáveis essas situações dentro e fora das escolas. Por isso, o perfil do/a professor/a Pankará está diretamente relacionado ao movimento das lutas deste Povo. Entre as características do jeito de ser educador/a, destacamos: ser pesquisador/a da história e cultura do Povo; ser conhecedor/a das tradições e nelas participar com orgulho; ter

\footnotetext{
${ }^{10}$ Ritual sagrado que conta com o cântico de rimas, denominada de toante.
} 
formação específica no campo da educação escolar indígena, partindo do princípio de que quem faz parte da educação escolar deve ser comprometido com a luta do Povo e com a formação de guerreiros/as fortalecedores/as da identidade étnica.

Nesse sentido, os projetos interdisciplinares são organizados a partir dos eixos norteadores do currículo escolar indígena, como: terra, identidade, história, organização e interculturalidade. Os eixos são formas de organização do espaço e do tempo escolares e significam expectativas de práticas de ação política/pedagógica. Entendemos que abordam aspectos fundamentais na educação escolar Pankará, pois fortalecem o projeto de sociedade sonhado por este Povo indígena. Esses eixos são fundantes na formação de guerreiros/as, pois, eles alicerçam os diversos projetos pedagógicos e políticos desenvolvidos na educação específica indígena (PANKARÁ, 2007).

A metodologia de pesquisa e desenvolvimento de projetos de intervenções didáticopedagógicos presente em todas as ações educativas do PIBID Diversidade, com a participação efetiva das lideranças, vai desde o fortalecimento da história, através da memória e de relatos orais, da relação da escola com o universo religioso e com os aspectos físicos, econômicos, políticos, sociais e culturais, sempre num movimento circular de aprender e ensinar.

Sendo assim, professores/as, estudantes, lideranças e comunidade são participantes ativos dos processos de ensino-e-aprendizagem, que resultam na elaboração de diversos materiais específicos de apoio pedagógico e, entre vários, destacam-se os já sistematizados e socializados nas práticas pedagógicas do Programa nas escolas do Povo, tais como: História das Aldeias Pankará; Fé, Crença e Ciência Pankará; As forças dos encantados à frente da Educação Pankará; A História de Luta do Povo Pankará; Organização Social e Política do Povo Pankará; A participação da comunidade na escola; por fim, Os saberes Pankará na educação escolar. Isso significa trazer para convivência escolar o respeito mútuo e tudo aquilo que é importante para a autonomia do Povo.

A amplitude da legislação brasileira e internacional, especificamente a Constituição Brasileira de 1988 (BRASIL, 1988), a convenção 169 da OIT (ORGANIZAÇÃO INTERNACIONAL DO TRABALHO, 2005) e a Declaração Universal de Direitos Humanos, aliaram-se à missão da extinta Secretaria de Educação Continuada, Alfabetização, Diversidade 
e Inclusão (SECADI) ${ }^{11}$ subsidiando os debates e discussão de garantia aos direitos já expressos de uma educação específica, diferenciada e intercultural para os Povos indígenas ${ }^{12}$.

Os/as universitários/as-Pibidianos/as vêm realizando o resgate da história de seu Povo junto com história da educação Pankará desde março de 2014, realizando entrevistas, rodas de diálogos, projetos pedagógicos e de intervenção, entre eles: 10 anos de Educação, Lutas e Conquistas (2014) e Os saberes Pankará na Educação Escolar (2015).

O processo de luta do Povo resultou na Organização Interna da Educação Escolar Indígena Pankará, com a participação de todos/as os/as professores/as refletindo e tomando decisões periodicamente sobre os problemas da educação, com relação ao desempenho das práticas pedagógicas.

Os/as professores/as são também lideranças, participam ativamente dos problemas nas aldeias e procuram refletir constantemente com os/as estudantes e responsáveis as situações dentro das escolas. Os/as educadores/as são indicados/as pelas lideranças e a comunidade com os critérios de morar na aldeia e participar das ações dos movimentos emancipatórios do Povo. Portanto, o perfil do/a professor/a Pankará está diretamente relacionado ao movimento das lutas do Povo.

As escolas, sendo espaços de aprendizagem das Aldeias, refletem a situação geográfica do Povo Pankará, por isso, a gestão tem interface com as relações sociais e familiares estabelecidas na comunidade, tanto no processo de decisão que ocorre a participação coletiva da comunidade, bem como na organização e no planejamento escolar. A gestão escolar desempenha seu trabalho em parceria com a organização do Povo, composta pelo conselho de anciãos, cacique, pajé, lideranças de aldeias e a própria comunidade. Nessa perspectiva, a formação política e pedagógica é um instrumento estratégico na busca da autonomia coletiva na construção do conhecimento e de fortalecimento da identidade Pankará.

\section{Narrativas de vida: estratégias de resistência e de luta}

\footnotetext{
${ }^{11}$ Criada em 2004, na presidência do governo Luís Inácio Lula da Silva, essa secretaria objetivava assegurar o direito à educação com qualidade e equidade, tendo políticas públicas educacionais voltadas para a inclusão social. Com ideais opostos, o então presidente Jair Messias Bolsonaro, por meio do Decreto ${ }^{\circ} 9.465$, de 2 de janeiro de 2019, instituiu mais um retrocesso no campo dos direitos educacionais, caminhando na contramão do reconhecimento da diversidade, da promoção da equidade e do fortalecimento da inclusão no processo educativo. ${ }^{12}$ A obra organizada por Paladino e Almeida (2012) discute os dilemas da educação escolar indígena na fronteira entre a diversidade e a igualdade.
} 
O grupo da terceira idade do Alto do Moura se reúne semanalmente, com vistas à partilha de experiências de vida, ao entretenimento, ao encontro intergeracional, pois participam alguns jovens, e aos aprendizados sobre a memória coletiva do Alto do Moura. É um coletivo que agrupa, aproximadamente, 30 (trinta) pessoas (mais mulheres que homens) que, além de rememorar as vivências infanto-juvenis e também da vida adulta, elaboram estratégias de resistência e luta pelo vigor do artesanato e pela dignidade do idoso.

Este grupo tem características, eminentemente, identitárias, políticas, religiosas e geracionais. As marcas identitárias revelam-se em se tratar, na maioria das vezes, de reuniões em que as histórias de vida dos sujeitos e narrativas que envolvem o trabalho com o barro enredam-se, imbricam-se. A vida cotidiana, o manuseio do barro, o rio Ipojuca, os casamentos e as lutas pela sobrevivência são constitutivos das suas identidades individuais e comunitárias.

O viés político é sublinhado nas falas desses sujeitos quando as narrativas dos enfrentamentos dos políticos locais e as lutas pela formação da Associação dos Artesãos e Moradores do Alto do Moura (ABMAM) têm espaço significativo. Ademais, os embates históricos dos artesãos com os atravessadores dos Shoppings Centers e com a própria Fundação de Cultura de Caruaru. Com os atravessadores que abarcam lucros exorbitantes, os/as artesãos/ãs defrontam-se para fazer valer os custos e o suor dos reais produtores das artes em barro; já a presença da Associação justifica-se pela ausência de políticas públicas definidas em prol desses sujeitos que dão reconhecimento sociocultural a Caruaru e à região agreste de Pernambuco. Para tanto, percebemos a presença significativa de uma motivação religiosa que produz, subjetivamente, nesses sujeitos, o enraizamento histórico e as forças embutidas para as lutas e enfrentamentos diuturnos por subsistência e dignidade. Estas forças mobilizadoras são externadas tanto no conteúdo das rezas como nas peças religiosas produzidas pelos/as mesmos/as, nas quais os santos e santas que refletem as "causas impossíveis" são-lhes representadas de forma recorrente.

O elemento geracional é também muito significativo à medida que as reflexões, brincadeiras e piadas vividas por eles mesmos, situam os idosos em suas reais condições de vida que se encontram hoje em sua faixa etária. Relatam sofrimentos das descriminações que padecem; ao mesmo tempo se alegram com o acumulado de experiências existenciais, simbólicas e artesãs que possuem como resultado dos anos vividos, celebrados e reinventados.

O cotidiano tem-lhes apontado que o domínio das artes de viver, de conviver e lutar por dignidade confere-lhes autonomia e condições reais de igualdade àqueles/as que, em nome dos 
títulos acadêmicos, não são capazes de desenvolver tais possibilidades e estratagemas políticos e cidadãos.

Os/as mestres/as da arte e da vida ensinam que as identidades são forjadas nas labutas diárias, nos enredos da existência e da perspicácia. A sabedoria de mulheres e homens é construída mediante uma vida híbrida, isto é, entre o medo e a ousadia de arriscar e acertar. "Eu, além de analfabeto, criei-me trancado vivo, [...] cismado que só saguim criado no meio do mato" (Mestre Vitalino). Esse pensamento, extraído da filosofia de vida do mestre do barro do Alto do Moura, atende a uma postura de curiosidade epistêmica assumida pela filosofia freireana. Pois, embora não tenha passado pelos bancos da sala de aula de uma escola, Vitalino criou-se trancado vivo, isto é, um ser curioso e atento aos movimentos e anseios de sua comunidade, atento e sensível às formas de criar e manifestar-se nas artes do barro.

Nessa mesma direção de Vitalino posiciona-se a fala do cangaceiro mais famoso dos sertões brasileiros, o Lampião: "O cangaceiro deve ser desconfiado e ardiloso como raposa, ter agilidade do gato, saber rastejar como a cobra e desaparecer como o vento" (Virgulino Ferreira da Silva, Lampião). A relação estabelecida entre a maneira de viver da natureza e o comportamento humano indicia o quanto o contexto sociocultural tece as identidades humanas. Demonstra, ainda, a relação atenciosa do Lampião para com a natureza das coisas, dos outros seres vivos. Uma relação que produz um aprendizado para a vida.

Apurado isto que é possível encontrar na fala de um grande líder da religiosidade popular, o "Padim Ciço" do Juazeiro, "[...] Só na velhice, pelas sinceras provas de lealdade durante toda vida do homem, é que pode-se ter a convicção da verdadeira amizade" (Pe. Cícero Romão Batista). Ou seja, revela-se a relação atenta, curiosa, experimental e cuidadosa para com as pessoas que convivemos diariamente para só depois de bastante tempo e avaliação acurada, concluirmos que elas são verdadeiras. E assim, tende-se a criar relações autênticas e não efêmeras.

Tais pensamentos engrossam o caldo da criação e manutenção de uma filosofia popular. Esse conjunto de sacadas extraídas da vivência cotidiana e da atenta relação com a natureza, com os causos da vida, os dramas da existência humana e das atividades laborais imprimem extratos de uma sabedoria autêntica e vigorosa, fomentada por mulheres e homens protagonistas na/da escola da vida.

\section{Procedimentos teórico-metodológicos}


No transcurso da produção do conhecimento, servimo-nos em primeiro lugar da observação participante, numa postura silenciosa, mas atenta, junto ao coletivo dos/as participantes, acompanhando e partilhando os itinerários indígenas e artesãos/ãs, seja nas rodas de diálogo, nas atividades acadêmicas, bem como nos comentários advindos de observações diversas ao longo dessa vivência.

A escolha das rodas de diálogo como cenário propício deveu-se ao fato de congregar um número maior de pessoas que, semanalmente, no caso dos/as artesãos/ãs do Alto do Moura e, mensalmente, para o Povo Pankará, encontravam-se para troca de experiências e percepções da vida, buscando entender a organização do pensamento popular e as suas condições de produção.

Compreendemos, a partir de Paul Ricoeur (1994), que documentar narrativamente a experiência não é só estar disposto a escrever, ler, reler, tecer comentários de outros. É uma conversação coletiva em torno dos relatos.

Nos encontros semanais com o grupo de idosos/as, as poesias populares estavam presentes, ora de improviso, ora anotadas em versos e lidas num ritmo sonoro, com tom conclusivo e condensador de sentidos, que remetiam aos repentistas das feiras populares do agreste pernambucano. Quanto aos momentos mensais com os/as indígenas Pankará, reuniamse os acontecimentos do tempo-comunidade ${ }^{13}$, transcorridos até a última estadia na universidade.

Os/as respectivos/as participantes procederam a autorização prévia para uso de sua real identidade. O uso do diário de campo possibilitou-nos reunir as anotações das falas, das pausas, dos causos e parte das poesias declamadas, somadas às suas impressões geridas pela literatura dos estudos pós-coloniais.

A trajetória de acesso ao conhecimento, aqui socializada, advém de uma elaboração cumulativa e integrativa da experiência, do modo de apreensão e de inteligibilidade da vida, a qual não datamos cronologicamente por compreender que o acesso aos diferentes modos e traduções, os quais comunicaram imagens de mundo, descrições das condições de vida,

\footnotetext{
${ }^{13}$ Organização curricular em alternância entre Tempo-Universidade e Tempo-Comunidade, entendendo-se por Tempo-Universidade os períodos intensivos de formação presencial no locus da formação e, por TempoComunidade, os períodos intensivos de formação presencial no território de moradia, com a realização de práticas pedagógicas orientadas, cf. Fonseca e Medeiros (2006).
} 
rompem com a linearidade e alargam os horizontes da temporalidade hermenêutica, compreendendo que o objetivo emancipatório da pesquisa, como parte integrante do processo de conscientização da formação, dá-se com e pela pesquisa e não alheia a ela.

Como afirma Passeggi (2016, p. 75), "Do ponto de vista axiológico, a dicotomia entre compreensão teórica e aplicação prática é substituída pela inclusão do objetivo emancipatório de conscientização e autonomização, que levará incondicionalmente em conta as experiências individuais de aprendizagem do sujeito da formação".

Em termos de procedimento, o processo de interpretação das informações, utilizamos o método autobiográfico pela potencialidade de diálogo entre o individual e o sociocultural, vinculando o momento da enunciação ou do enunciado em elementos que vão se desenhando na relação das narrativas com seus contextos (SANTAMARINA e MARINAS, 1994).

Essas lentes interpretativas forneceram-nos lampejos de sentidos, tanto em se tratando das condições da produção das cosmovisões indígenas e artesãs, como dos processos de elaboração do pensamento popular.

No campo das contextualidades produtoras de sentidos algumas categorias foram centrais, tais como: corpo - cotidiano, indissociabilidade e interinfluências. Elas postas, organicamente, foram fundamentais no intento de superar o conhecimento monológico, produzido pelo paradigma das certezas, da ordem, cuja base é eminentemente racionalista (DOSSE, 2009; MIGNOLO, 2010; KINCHELOE e MACLAREN, 2008; SANTOS, 2010).

As narrativas dos sujeitos artesãos e do Povo Pankará demandam diversas estratégias de significados uma vez que os teores das suas falas denunciam os universalismos que esmaecem as originalidades dos sujeitos e territórios produtores de saberes; ao mesmo tempo apontam para conexões de sentidos entre espacialidades e temporalidades diversas, requerendo polissemias e relações complexas entre o material e o simbólico, o passado presente e o futuro latente e mobilizador do presente, além das interintextualidades que compreendem a relação entre diferentes narrativas.

Tudo isto para dizer que a ciência moderna, que emerge no século XVI, teve o seu papel precípuo nessa empreitada de ruptura entre o sujeito do conhecimento e o sujeito biográfico, buscando, simultaneamente, compreensões filosóficas dos sujeitos artesãos (leituras de mundo) e suas formulações através da organização dos seus modos de autoexpressão de ser, de fazer e de se relacionar no mundo. 
Ou ainda, como afirma Santos (2002, p. 81), a respeito do sujeito, "A ciência moderna consagrou o homem como sujeito epistémico, mas expulsou-o enquanto sujeito empírico".

O uso das técnicas da análise de conteúdo (BARDIN, 2016) foi feito mediante a exploração do material, oriundo da observação participante e dos diários de campo, a classificação dos termos e enunciados por categorias axiais que se demonstravam portadoras de significados relativos tanto às cosmovisões dos sujeitos artesãos e indígenas Pankará, como das formas inter-relacionais de organização de sentidos e linguagens.

Deste modo, obtivemos tanto os elementos indicadores das fontes das visões de mundo do Povo Pankará e dos/as artesãos/artesãs do Alto do Moura, como do modo associativo, orgânico e não linear das formulações dos seus pensamentos, ideias, lutas e afirmações das individualidades e das suas identidades em movimento.

\section{A dinâmica do aprender e ensinar a partir da ação do PIBID Diversidade nas escolas do Povo Pankará}

O Povo indígena Pankará, situado no sertão de Pernambuco/Brasil, anuncia em sua compreensão de mundo e em suas práticas político-pedagógicas, aspectos sugestivos e decoloniais nos aspectos epistemológicos, metodológicos e escolares.

Em se tratando dos constructos epistemológicos, a curiosidade, a sobrevivência material e simbólica e as realidades espaço-temporais imbricam-se, gerando sentidos, correspondências, forças identitárias e modos próprios de conhecer associado ao ser e ao fazer.

O traço decolonial caracteriza-se pela natureza coletiva da construção do conhecimento em que as atenções epistêmicas e os teores curriculares são desenvolvidos, vistos e analisados por todos/as, isto é, professores, anciãos, lideranças e bolsistas do PIBID Diversidade.

A noção de sujeito coletivo está em voga em que o labor dos saberes e dos seus múltiplos significados é patrimônio e tarefa dos seus pertencentes, pois as relações de poder são compartilhadas. Os/as universitários/as-bolsistas não são tratados como alguém que tem bagagem conceitual superior, mas diversa que dialoga tecendo a ecologia de saberes (SANTOS; MENESES, 2010).

A metodologia vivenciada pelos Pankará ganha destaque, tanto no modo coletivo de elaboração e sistematização do conhecimento, quanto nos projetos interdisciplinares que são 
desenvolvidos mediante um elenco de eixos norteadores que abrangem os aportes de vida, de luta e de compreensão desta população historicamente invisibilizada.

Os projetos de intervenção não se configuram em práticas de extensão universitária, tampouco em atividades pontuais e isoladas. Eles adquirem um status epistemológico, robustecendo a investigação científica, os interesses políticos de afirmação dessa população e os conteúdos de ensino-aprendizagem. É digno de nota que esses projetos de intervenção em sua relevância sociocultural e política-educacional são eleitos coletivamente e indicam uma análise prévia da sua pertinência, influência, alcance e continuidade na vida e realidade dos Pankará.

Desse modo, o fazer e o viver, o conhecer e o ser, bem como a ciência moderna e os saberes ancestrais têm paridade, implicação recíproca e desdobramentos nas realidades Pankará, no reforço da legitimidade dos seus saberes primordiais e no exercício dos conhecimentos que partem da prática e por ela e para ela materializam-se e garantem o porvir dessa população inferiorizada pelos conhecimentos da ciência positiva e pelas políticas coloniais.

A educação escolar indígena, por sua vez, diferencia-se da tradicional, quando escola e comunidade têm uma ligação indissociável, complementar. Ou seja, as questões indígenas não são tratadas de forma transversal e compartimentada, mas inserida na rotina da escola, indicando uma estrita ponte, intercâmbio entre a comunidade como chão mais amplo das aprendizagens, e a escola como espaço de transmissão e de aprofundamento da sabedoria acumulada às novas gerações Pankará.

Sem negar ou substituir o papel específico do docente, a tarefa do ensino é estendida e partilhada com os anciãos, com as lideranças locais e pessoas outras referenciais da comunidade. Outro diferencial da educação escolar indígena evidencia-se na larga presença do Sagrado através dos saberes da natureza, da força dos encantados e da compreensão teofânica, manifestativa daquele em lugares e pedras específicos no território Pankará. Há uma íntima relação entre os ancestrais e as populações atuais, entre os saberes dos antepassados e os ensinamentos necessários para a condução atual da vida da coletividade Pankará.

Esse movimento em torno da educação escolar indígena contribui enquanto constitui-se num instrumento estratégico na busca da autonomia coletiva, tanto na construção do conhecimento, como no fortalecimento da identidade Pankará. 


\section{Elementos que constituem as visões de mundo do Povo Pankará e dos/as Artesãos/ãs do Alto do Moura}

Um aspecto orientador desse entendimento é montado e articulado a partir da dinâmica das interinfluências em que as espacialidades, as temporalidades, os diversos sujeitos e modos de pertencimentos e de cumplicidade, além da íntima relação entre material e simbólico, o mistério e as revelações, assim como heranças coloniais se alinham e se interpenetram.

Em relação aos espaços, há uma conjugação entre as casas, as ruas, o campo, a natureza e a radical presença do sagrado. Ora se percebe em separado, mas, predominantemente, é entendida de forma articulada, mesmo mantendo tensões e fronteiras. Em cada espaço há especificidades, mas o que se esconde é o alinhamento afetivo, de pertencimentos que transversaliza, que ultrapassa qualquer formulação social ou etiqueta cultural. O que vale, o que conta em termos de significados para os sujeitos artesãos e indígenas é a confiança, é a valoração das relações de intimidade, de cumplicidade, de consideração dos atores em voga. A lógica da intimidade prevalece sobre as distinções e separações de espaços e tempos indicando fidelidade das relações, apoio recíproco fiducial, que se traduz em forças resistentes e criativas nas lutas do cotidiano.

É nesse diapasão que iremos situar a relevância que tem os compadriamentos, isto é, as pessoas da classe popular, marcadas pela cultura rural, que instalam modos de relação familiar ainda inspiradas no convívio feudal em que a parentela de sangue é ampliada em nível de consideração e apreço, quando várias pessoas de laços não-consanguíneos são assumidas como sendo incorporadas à árvore genealógica em termos de tamanho apreço, consideração, intimidade e pertencimento. São os compadres e as comadres que se equivalem aos irmãos e irmãs mais próximos, cúmplices e partícipes das esferas da vida que se desenrola no cotidiano.

Um aspecto prevalecente nessa relação entre espacialidades e temporalidades é o da fé religiosa, especialmente traduzida pelo entendimento da confiança em Deus que serve como lenitivo emocional, mas também como uma senha de credibilidade da honestidade moral desses possíveis novos interlocutores. O ateísmo carrega a sombra do descrédito desumanizador e como algo germinador de crueldade e de maldade humanas expostas. Aspecto ainda bastante presente no imaginário popular indígena e artesão em que a cosmovisão rural tem predominância e o sagrado tem força de comando de comportamentos, costumes, valores e modos de vida. 
Faz parte também desse novelo de significados a proximidade entre vida e morte. O que a modernidade tanto distingue e distancia como elementos integrantes da existência dos viventes, os sujeitos artesãos e indígenas alinham a vida portando a morte no sentido de que os mortos, os antepassados, são evocados sem protocolos, sem cerimônias; os velórios são vivenciados no interior das residências e o cemitério local é bastante cuidado e frequentado pelos habitantes locais do Alto do Moura e das aldeias do Povo Pankará.

Outro aspecto presente é a distinção entre noite e dia mesmo entre aqueles que vivem há bastante tempo na cidade. Em relação às noites, os espectros das tochas luminosas que apareciam e faziam medos, bem como os contos dos mais velhos que imprimiam uma certa paura grupal mantém-se com bastante vivacidade e presença. $\mathrm{O}$ dia, que começava bem de madrugada nos roçados, remonta à ideia e sentimentos de trabalho, de dureza no enfrentamento do sol e das chuvas sazonais, além de sinalizar marcas imprescindíveis de gente não preguiçosa. Durante a noite se descansa, e no dia desperta-se cedo para o trabalho, para a produção de algum modo.

Como penúltimo aspecto da cosmovisão dos/as artesãos/ãs e também do Povo Pankará, destacamos o significado da festa, sendo esta marcada pela abundância da comida, pela reunião dos amigos e vizinhos além dos possíveis transeuntes que eventualmente apareçam. Outro detalhe relevante é o traço da inclusão: os convidados e os demais, todos participam da festa que pode durar noites inteiras. Sem esquecer que o dado da festa aparece em um calendário anual, no entanto, em quaisquer comemorações ocasionais, por causa de algum acontecimento que indique vitória, superação, premiação, conquista política, sendo de natureza individual ou coletiva, o dado festivo tem espaço devido. O espírito festivo e celebrativo da vida está presente todo tempo na vida desses sujeitos em que resistência e criatividade são companheiras complementares.

Por fim, no tocante, em especial aos ceramistas, em relação à leitura e à escrita, podese perceber um duplo movimento: por um lado, admiram quem domina a leitura e a escrita; doutro lado, fazem-se valer mediante o discurso que não precisaram de leitura e escrita para viajar para países distantes, para participar de exposições nacionais e internacionais, bem como na arte de administrar a vida perante muitas agruras em suas itinerâncias de longas datas.

Nesse horizonte, entendemos que as visões de mundo desses sujeitos artesãos e indígenas são marcadas por interinfluências de várias dimensões e de múltiplas naturezas que, simultaneamente, estão em movimento reunindo diversos aspectos, tais como: histórias de vida, 
experiências acumuladas, falas e modos de vida de figuras emblemáticas que eles foram conhecendo pela vida afora. Além das influências oriundas da cidade ou do campo, das espacialidades e das temporalidades diversas, dos sofrimentos próprios e dos episódios diários. Em sendo assim, o cotidiano serve como espaço-tempo de aprendizagens, de ressignificações, de resistências políticas e de reinvenções artístico-culturais, quando as observações, as associações interpretativas e a densidade valorativa são ferramentas e resultados das aprendizagens e ensinagens desenvolvidas.

\section{Dinâmicas organizativas da educação escolar indígena e do pensamento popular}

Como resultado destas reflexões e vivências artesãs e indígenas foi bastante significativa a compreensão e a lógica interna do pensamento popular que atravessa as respectivas leituras de mundo que se bifurcam a partir desses atores/atrizes sociais. A lógica prevalecente desenhase e movimenta-se de três modos: (i) de modo indireto; (ii) com argumentos de natureza associativa; e, (iii) de modo que comporta densidade sintética e poética.

\section{(i) De modo indireto}

A figura de suposto terceiro sujeito no teor da conversa que adquire força e identidade para encobrir a própria vergonha ou constrangimento da pergunta curiosa e invasiva ou ainda do desconforto de solicitar um dinheiro emprestado é identificado nas narrativas socializadas.

\footnotetext{
"Comadre Zefa, gostaria de perguntar a Senhora, por mim não, sobre a decisão que deu errada na comunidade de Taquara de Baixo..." (D. Mariquinha).

"Eu fiquei pensando em casa se eu viesse aqui e pedisse à senhora R $\$ 100,00$ emprestado se daria certo? A vida é assim põe a gente em cada uma situação. Todo mundo passa por isso..." (Sr. José).
}

Nesses recortes de fala, a interlocução intersubjetiva serve de amortecedor emocional e de um erguimento de uma cortina de fumaça como anteparo da autoimagem do propositor conversacional.

São falas que se organizam utilizando um modo narrativo indireto, ou seja, os sujeitos falantes comunicam seus desejos e/ou solicitações servindo-se de analogias, de uma cena improvisada em que o eu falante se transfere para uma imagem de um terceiro interlocutor e 
não de forma direta nas manifestações de solicitações ou de posicionamentos pessoais. Não que se ausente dos posicionamentos, mas transparece de forma dissimulada, sutil, acerca do que pensa, defende e acredita. O pensamento do sujeito, principalmente em situações de conflito, emerge mediante comparações aproximativas, por analogias, com o intuito de não criar embaraços para a sua vida, perseguições e pressões externas, talvez manchas na sua autoimagem.

Percebemos como um jogo sutil, mas, profundamente, atento e ativo por parte do interlocutor popular, evidenciando-se que a forma metafórica e transferencial é caraterística da linguagem popular. Cunhamos essa atitude e forma de pronunciar-se como um jogo de sutilezas dos subalternizados.

\section{(ii) Argumentos de Natureza Associativa}

As linguagens coletivas são eivadas de falas e, sobretudo, de gestos. A força gestual é mais significativa que a verbal, pois o corpo tenta dizer mais que a pronúncia de um discurso ordenado, fechado e determinista. Isto porque os discursos populares estão sedimentados diretamente na vida, no cotidiano e em tudo aquilo que se observa, se vive e faz sentido para os sujeitos artesãos.

\footnotetext{
"O cangaceiro deve ser desconfiado e ardiloso como raposa, ter agilidade de gato, saber rastejar como cobra e desaparecer como o vento" (LAMPIÃO).

"Tem pessoas que parecem ser mofinas como cobras confinadas; outras parecem como um cambão de milho: vão pela força do vento sem rua e nem endereço na vida" (D. Miúda).
}

A natureza e os animais com os seus ritmos e constituições servem de referência de sentido e de significados para exprimir as impressões da vida e as análises compreensivas dos modos de viver dos sujeitos populares. Manifestam formas os gingos humanos para driblar as leis sociais impostas, a moralidade estóica e os confrontos que a dureza do cotidiano demanda, especialmente, para os sujeitos sociais que forçosamente são pressionados a responder questões e situações vexatórias sem os acessórios de uma lógica elaborada nos moldes formais e escolares.

A cada vez que se pergunta sobre algo ou se sugere alguma explicação, entendimento, os/as artesãos/ãs e indígenas, em geral, respondem de modo associativo evocando histórias de vida, fatos análogos, fenômenos da natureza ou parábolas que possam anunciar, referendar 
significados, argumentos e sentidos perante a questão que lhe foi solicitada. A resposta não aparece em termos de definição direta e precisa, mas de modo circunferencial, aparentemente tangencial, no entanto, pertinente e esclarecedor. Os fatos da vida, os segredos da natureza, os conselhos dos mais velhos e os acontecimentos da comunidade servem de base interpretativa para o conjunto de compreensões, explicações e mobilizações afirmativas, existenciais e políticas dessa população.

Desse modo, interpretamos que os autores dos discursos são individuais, porém, o teor é coletivo, os conteúdos são construções tecidas sob múltiplas influências em diferentes tempos, situações e episódios que os sujeitos foram sedimentando as intertextualidades da vida. Portanto, consideramos a comunidade um intelectual coletivo, no sentido de que uma ideia se fixa na memória coletiva à medida que associada à vida cotidiana, aos fatos marcantes e às lições de vida que se erigem na e da vida em comunidade.

\section{(iii) Densidade Sintética e Poética}

Outro aspecto saltitante aos nossos olhos foram os modos como esses coletivos no término das rodas de diálogo, dos encontros festivos e mesmo nas conversas coloquiais, a complexidade da vida é compreendida e socializada em forma de poesia popular (cordel), de versos rimados e ritmados, de provérbios, que redundam de forma simples, direta e em caráter de síntese, os conteúdos discutidos, as abordagens feitas por diversos interlocutores, bem como os mistérios contínuos que indicam abertura de coração e de mente perante cada novo fato surpreendente.

\footnotetext{
"A gente conhece uma pessoa de coração fechado através de um olhar apagado" (D. Cleonice).

"Como se vive a vida?... Ateimando. Zuando. E sentindo. Como se vence?... Questionando... (Mestre Galdino).
}

A cosmovisão desses sujeitos populares, indígenas e não-indígenas, é tecida mediante uma observação atenta e direta da existência, cuja sede é o cotidiano e as vivências imediatas. Delas se extraem as leituras de mundo, da complexidade humana e dos conteúdos das suas filosofias, isto é, das suas buscas de significados para entender e organizar a vida nas condições reais e sempre de modo temporário, curto e aberto a novas considerações. Isto traduzido de forma rimada ou num tom sentencial marcador de verdades a serem consideradas pelas gerações 
vindouras. Há de se notar que a veia poética não falta, não obstante se tratando de fenômenos humanos sombrios e embaraçosos.

A síntese e a poesia se entrelaçam. Em vez de um conjunto de palavras de significado unívoco e enxuto, deslancha-se um enovelado de palavras usuais associadas à cozinha, à natureza e à vida prática organizado com uma moldura estética, suave e contundente acerca das questões que são postas e ressignificadas. Em geral, há o assentimento do grupo mediante os aplausos, o menear das cabeças e a atmosfera de festa que reveste cada encontro dessas comunidades. O improviso tem predomínio e sinaliza uma busca contínua de significados, que não caracteriza espontaneísmos, pois, está todo tempo ancorado nas questões que circundam, forjam e transversalizam a vida.

\section{Contribuições destas reflexões para a educação escolar indígena e popular}

Em se tratando de busca de compreensão das condições de produção do conhecimento, da sua geopolítica, e dos modos de elaboração dos saberes populares, campesinos, acessamos tanto um aspecto como outro, advindo das contribuições para as Epistemologias do Sul quando caracteriza as cosmovisões dos povos do campo e as suas formas específicas de autoexpressão e das lutas afirmativas em suas trajetórias de vida.

Universo Cultural artesão/campesino propiciador da Educação Popular: este estudo traz à tona os meandros, as sutilezas e modos constitutivos das visões de mundo desses sujeitos que lidam com o roçado e com o barro, ao mesmo tempo, que desenham as suas linguagens e modos de resistir, de criar e de se reinventar continuamente. Para Brandão (2007), inteligir a cultura popular é condição fundamental para melhor acessar as formas, os processos e os modos aprendentes/ensinantes dessas populações.

Educação de Jovens de Adultos: por ser uma pesquisa elaborada, marcadamente por pessoas da terceira idade, a educação de jovens e adultos pode se beneficiar, pois, o universo cultural está bastante expresso e os modos de construir e de socializar criativamente os conhecimentos adquiridos, associados e ressignificados estão presentes indicando novas possibilidades.

A educação escolar indígena melhor habilita-se no trato de melhor preparar as novas gerações indígenas na postura de escuta e acolhida no jeito de raciocinar, de construir ideias e visões de mundo dos anciãos, bem como dos seus modos de expressão e de comunicação 
reunindo a associação com o cotidiano, o mundo dos animais, com os ritmos e falas da natureza e dos encantados como portas reveladoras de uma sabedoria ancestral.

\section{Considerações finais}

Este caminho reflexivo possibilitou a descolonização epistêmica à medida que fomos elucidando a descolonização da mente, isto é, a passagem de uma lógica colonial para o entendimento de que muitos mundos coexistem, interagem e se interinfluenciam.

Há que se ter uma ampliação do olhar, isto é, a verificação de que as leituras de mundo e dos/as participantes não são simplistas, superficiais e, tão-somente, marcadas por superstições, senso comum raso e repetições pendentes dos antepassados. Percebemos e compreendemos que o engenho imaginativo popular e indígena é inventivo, contínuo, aberto e complexo, pois, demanda a difícil tarefa de articular, simultaneamente, diferentes temporalidades, espacialidades, interlocuções, sentidos e dimensões de diversos níveis e dimensões da vida (subjetividade/objetividade; material/simbólico; familiar/estranho; fé e cotidiano; luzes/sombras; luto/festa; dúvidas/decisões etc.).

Possibilitou-nos a vivência do paradigma das incertezas em que a concepção positivista das ciências e da pesquisa em educação não tem mais preponderância; começa a ruir. A presença da interculturalidade ${ }^{14}$ e, sobretudo, da transdisciplinaridade, constituem-se ferramentas fundamentais para se inteligir, interagir e intervir de modo dialógico e democrático do conhecimento, cujos lugares de enunciação e os interlocutores originam-se em diferentes topos, idades, situações e de formas associativas diversas, imponderáveis, que constituem e transversalizam as dimensões da vida que se mostram em saltos e constantemente surpreendentes.

Nesta compreensão mais ampliada da Educação Escolar Indígena, em particular, do Povo Pankará, com a presença do PIBID Diversidade, iniciado em 2011, pela Coordenação de Aperfeiçoamento de Pessoal de Nível Superior (CAPES), tem fortalecido estes modos aprendentes e ensinantes do Povo Pankará, quando os/as universitários/as-bolsistas e

\footnotetext{
${ }^{14}$ Nos baseamos no conceito de interculturalidade crítica, compreendida por Walsh (2012),como "[...] proyecto político, social, ético y también epistémico - de saberes y conocimientos -, proyecto que afianza para la transformación de las estructuras, condiciones y dispositivos de poder que mantienen la desigualdad, racialización, subalternización e inferiorización de seres, saberes y modos, lógicas y racionalidades de vida."
} 
supervisores/as ligados/as a este Programa governamental contribuem e ampliam a reflexão de mundo com as práticas indígenas já existentes.

Outrossim, o PIBID Diversidade tem possibilitado a visibilidade dos Povos indígenas ${ }^{15}$ subalternizados à medida que traz discussões de natureza decolonial sobre os modos de viver, de aprender e de ensinar dos Pankará.

Essa abordagem das Ciências Sociais é desenvolvida pelos/as universitários/asbolsistas, pelos/as supervisores/as e pelos/as coordenadores/as. Nesta direção, os olhares desses/as atores/atrizes sociais são convidados/as a enxergar e aprofundar os sentidos que as práticas educativas, envolvendo escola-comunidade-e-universidade têm efetivado ao longo dos tempos.

Desse modo, os esteios metodológicos que organizam as formações pedagógicas e os planejamentos curriculares partem da reflexão de que os nossos saberes são também para os Pankará um patrimônio vivo, coletivo e fontal de epistemologias e metodologias outras.

Para finalizar, retomo a tríplice dimensão que constituíram as formas diferenciadas de ensinagens e aprendizagens dos Pankará e ceramistas do Alto do Moura, corpo - cotidiano, indissociabilidade e interinfluências, constituindo-se, sobretudo, na revalorização dos modos próprios de fazer educação, tecendo um estranhamento ao olhar decolonial ao revisitar os referenciais de pensar e de produzir conhecimentos.

\section{Referências}

ARROYO, Miguel González. Outros sujeitos, outras pedagogias. 2. ed., Petrópolis: Vozes, 2014.

BARDIN, Laurenci. Análise de conteúdo. Tradução: Luís Antero Reto. São Paulo: Edições 70, 2016.

BRANDÃO, Carlos Rodrigues. O que é Educação Popular. Col. Primeiros Passos, n. 318, São Paulo: Brasiliense, 2012.

BRASIL. Constituição da República Federativa do Brasil. Brasília/DF, 5 de outubro de 1988.

DOSSE, F. O desafio biográfico. Escrever uma vida. Tradução Gilson César C. de Souza, São Paulo: Edusp, 2009.

FREIRE, P. Educação e mudança, 31. ed. Rio de Janeiro: Paz e Terra, 2008.

\footnotetext{
${ }^{15}$ Para ampliar a compreensão do Programa, cf. Silva; Silva; Falcão (2018).
} 
KINCHELOE, J. L.; MACLAREN, P. Repensando a teoria crítica e a pesquisa qualitativa. O planejamento da pesquisa qualitativa: teorias e abordagens. 2. ed. Porto Alegre: Artmed, 2008. p. 281-313.

FONSECA, A. M.; MEDEIROS, M. O. Currículo em Alternância: uma nova perspectiva para a Educação do Campo. In: QUEIROZ, J. B. P. et al. (Org.). Pedagogia da Alternância: construindo a Educação do Campo. 1. ed. Goiânia: Editora da UCG; Brasília: Ed. Universa, 2006.

MALDONADO-TORRES, Nelson. Sobre la colonialidad del ser: contribuicones al desarrollo de um concepto. El Giro Decolonial: reflexiones para una diversidade epistémica más allá del capitalismo global. Bogotá: Siglo del Hombre Editores, 2007.

MIGNOLO, W. Desobediencia epistémica: retórica de la modernidad, lógica de la colonialidad y gramática de la descolonialidad. Buenos Aires: Ediciones del Signo, 2010.

. El Pensamiento Decolonial. El Giro Decolonial: reflexiones para una diversidad epistémica más allá del capitalismo global. Bogotá: Siglo del Hombre Editores, 2007. p. 25-46.

PANKARÁ. Projeto Político Pedagógico das Escolas Pankará. Serra do Arapuá, Carnaubeira da Penha/ PE, 2007.

PASSEGGI, Maria da Conceição. Narrativas da experiência na pesquisa-formação: do sujeito epistêmico ao sujeito biográfico. Roteiro, Joaçaba, v. 41, n. 1, jan./abr. 2016. pp. 67-86.

RICOEUR, Paul. Tempo e narrativa, v. 1, Campinas (SP): Papirus, 1994.

SANTAMARINA, C. MARINAS, J. M. Histórias de vida e história oral. In: Delgado, J. M., \& Gutiérrez, J. (Coords.). Métodos y técnicas cualitativas de investigación en ciencias sociales. Madrid: Síntesis, 1994.

SANTOS, Boaventura de Sousa; MENESES, Maria Paula (Orgs.). Epistemologias do Sul. São Paulo: Cortez, 2010.

Cortez, 2002.

A crítica da razão indolente. Contra o desperdício da experiência. 4. ed. São Paulo:

SANTOS, Maria do Carmo Gonçalo. As contribuições do currículo da formação para a prática pedagógica docente com gênero e sexualidade na educação básica. Tese (Doutorado em Educação) - Programa de Pós-Graduação em Educação, UFPE, 2016.

SILVA, Everaldo Fernandes da. Processos aprendentes e ensinantes dos/as artesãos/ãs do Alto do Moura: tessitura de vida e formação, Tese de Doutorado, Programa de PósGraduação em Educação, UFPE, 2011.

SILVA, Jaqueline Barbosa da; SILVA, Everaldo Fernandes da Silva. Experiência e processos formativos na rede indígena de Pernambuco: o Pibid Diversidade e as Leituras Decoloniais, Revista Interritórios, V. 1, N. 1, UFPE-Caruaru/PE, Brasil, 2015. Disponível 
em: \&lt;http: https://periodicos.ufpe.br/revistas/interritorios/article/view/5014\&gt;. Acesso em:

nov./2020.

; _ _ FALCÃO, Lúcia Barbosa. Vozes do PIBID Diversidade: epistemologias em diálogo, Revista Interritórios, v. 4, n. 7, 2018. Disponível em: <https://periodicos.ufpe.br/revistas/interritorios/issue/view/2694>. Acesso em: maio/2020.

WANDERLEY, L. E. Educação Popular: metamorfoses e veredas. São Paulo: Cortez, 2010.

WALSH, Catherine. Interculturalidad y (de)colonialidad: Perspectivas críticas y políticas. Visão Global, Joaçaba, v. 15, n. 1-2, p. 61-74, jan./dez. 2012.

YOUNG, Michael, F. D. O Futuro da educação em uma sociedade de conhecimento: o argumento radical em defesa de um currículo centrado em disciplinas. Revista Brasileira de Educação, São Paulo, v. 16, n. 48, p. 609-623, set./dez. 2011.

Submetido em 16 de fevereiro de 2021.

Aceito em 25 de maio de 2021.

Publicado em 16 de julho de 2021. 